\title{
É o Naturalismo Biológico uma Concepção Fisicalista?
}

\author{
TÁRIK De ATHAYde Prata \\ Universidade Federal de Pernambuco
}

\begin{abstract}
This paper is concerned with the question as to whether biological naturalism (John Searle's solution for the mind-body problem) can be construed as a physicalist account of the mind. Despite defending physicalism in connection with particulars (section 2), Searle accepts the dualists' basic argument for the irreducibility of mental properties (section 3). However, Searle is unable to substantiate his claim that such irreducibility is compatible with physicalism (section 4). This being the case, his theory about the mind is shown to be a variety of property dualism.
\end{abstract}

Keywords: Physicalism; logical possibility; property dualism.

\section{Introdução}

Desde o início da década de 1980, o importante filósofo norte-americano John Rogers Searle tem defendido uma determinada teoria para explicar a relação entre os fenômenos mentais e o mundo físico (isto é, uma determinada solução para o problema ontológico na filosofia da mente, o problema mente-corpo - cf. Churchland 2004, p.17), teoria que ele chama de "naturalismo biológico" (cf. Searle 1983, p.264 [366]; 1992, p.1 [7]). ${ }^{1}$ Em escritos mais recentes, Searle caracteriza a teoria em termos de quatro teses fundamentais (cf. Searle 2004, p.113-4; 2007, p.170-1):

(1) Irredutibilidade ontológica: "a consciência assim definida é um fenômeno real no mundo real. Ela realmente existe e nós não podemos nos livrar dela excluindo-a por definição, reduzindo-a a algo outro ou fingindo que ela não existe realmente" (2007, p.170).

(2) Redutibilidade causal: "estados conscientes são inteiramente causados por processos neurobiológicos de nível inferior no cérebro. Estados conscientes são, portanto, causalmente redutíveis a processos neurobiológicos" (2004, p.113).

(3) Natureza de propriedade sistêmica: "estados conscientes são realizados no cérebro como características do sistema cerebral e, portanto, existem a um nível mais elevado do que o de neurônios e sinapses" (2004, p.113-4).

(4) Eficácia causal: "a consciência funciona causalmente na produção de movimentos corporais e outros efeitos físicos no mundo" (2007, p.171).

Trata-se de uma teoria que vê a consciência como um produto causal da atividade do cérebro (cf. Searle 1980, p.453), uma atividade biológica, o que tornaria Principia 16(2): 255-276 (2012).

Published by NEL — Epistemology and Logic Research Group, Federal University of Santa Catarina (UFSC), Brazil. 
compreensível que a consciência seja capaz de causar outros fenômenos biológicos (cf. Searle 1983, p.264 [366]) como nossos movimentos corporais. Ao mesmo tempo em que seria causada pela atividade cerebral, a consciência seria uma propriedade sistêmica do cérebro, isto é, uma propriedade realizada no sistema cerebral. ${ }^{2}$ Mas, mesmo sendo uma propriedade do cérebro, a consciência teria um modo de existência (uma ontologia) diferente, subjetiva, que a tornaria irredutível a quaisquer fenômenos objetivos (como são os processos cerebrais).

Sobre essa teoria da mente, existem na literatura interpretações bastante díspares. Comentando alguns de seus primeiros escritos, intérpretes como U. T. Place (1988, p.208) e J. Schröder (1992, p.101) consideraram Searle como um representante do fisicalismo mais tradicional (Schröder vincula o naturalismo biológico à teoria da identidade de Herbert Feigl). Já autores como P. Stich (1987, p.133) e A. Kemmerling (1994, p.438) vêem uma grande convergência da teoria de Searle com o dualismo cartesiano. Por outro lado, alguns intérpretes, como S. Cunningham (2000, p.34) e K. T. Maslin, (2001, p.175 [170]), percebem similaridades do naturalismo biológico com o fisicalismo não-redutivo. A simples existência de uma diversidade tão grande de visões já é um forte indício de que a solução de Searle para o problema mente-corpo não é uma concepção claramente articulada e, no meu modo de entender, ele realmente abre margem para essas interpretações tão heterogêneas.

Em seus primeiros escritos sobre filosofia da mente, Searle expressa uma forte sintonia com o reducionismo. ${ }^{3}$ Por outro lado, em diversos momentos ele atribui aos fenômenos mentais características tão especiais que parecem torná-los essencialmente diferentes dos fenômenos físicos. ${ }^{4}$ Ao mesmo tempo, seu propósito é, explicitamente, conciliar a ideia de que o mundo físico é o nível fundamental da realidade com as características típicas da mente - o que apoia a visão de Cunningham e de Maslin, de que ele tenta articular uma forma de fisicalismo não-redutivo. ${ }^{5}$

Mas se temos indícios tão heterogêneos, como entender o naturalismo biológico? Trata-se de uma forma de dualismo? Ou estamos diante de um fisicalismo reducionista? É possível assumir a posição intermediária de que Searle defende uma forma de fisicalismo que não chega ao extremo do reducionismo? As ambiguidades da teoria tornam difícil situá-la no debate mente-corpo, levando muitos a considerarem que ela é incoerente, um misto de dualismo e de fisicalismo. ${ }^{6}$ Nesse sentido, é interessante observar a avaliação de Jaegwon Kim sobre o naturalismo biológico:

Ao menos no caso do problema mente-corpo, a solução de Searle me parece carregada de ambiguidades e dificuldades - de tipos que não são realmente novos. [...] eu creio que o naturalismo biológico, que fornece para ele o esquema metafísico básico, precisa ser repensado desde os seus fundamentos. (Kim 1995, p.189)

Apesar de considerar que a teoria de Searle, na sua forma mais atual, possui elementos de reducionismo, opto por deixar essa interpretação de lado, pois ela me 
parece fruto de certas imprecisões da teoria, que poderiam ser corrigidas com algum esforço. ${ }^{7}$ Restam então o dualismo e o fisicalismo não-redutivo, e o simples fato de que essas duas concepções, no fundo, são muito próximas (podendo até mesmo ser interpretadas como diferentes variações de uma mesma concepção ${ }^{8}$ ) dá certa plausibilidade à hipótese de que o naturalismo biológico se encaixa em uma delas (já que o fisicalismo não redutivo pode ser considerado como uma forma atenuada de dualismo, é plausível que a teoria de Searle esteja em algum lugar entre ambos). O importante filósofo australiano David Chalmers (provavelmente o maior representante do dualismo de propriedades em nossa época) ${ }^{9}$ afirma que Searle tenta articular uma forma de fisicalismo não-redutivo, mas que por incoerências internas termina caindo no dualismo de propriedades (cf. 1996, p.164).

De fato, não há espaço para se supor que o naturalismo biológico defenda um dualismo de substâncias, já que Searle atribui caráter físico a tudo o que existe concretamente no espaço e no tempo ${ }^{10}$ e recusa o dualismo de substâncias cartesiano como incompatível com os conhecimentos científicos atualmente disponíveis (cf. Searle 2004, p.42). Isso significa que ele adere a um fisicalismo a respeito dos particulares ${ }^{11}$ que, entretanto, é perfeitamente compatível com um dualismo a respeito das propriedades. E, nesse sentido, é importante ter em vista que a tese de que todas as entidades concretamente existentes no tempo e no espaço são físicas, não constitui um fisicalismo pleno, caso ela seja acompanhada pela aceitação de que algumas propriedades dessas entidades são independentes das propriedades físicas. Mesmo se alguém aceita que todas as propriedades mentais são instanciadas por particulares físicos, esse alguém ainda tem a possibilidade de aceitar um domínio misterioso de propriedades mentais. $^{12}$

A idéia que dá a especificidade do fisicalismo não-redutivo como uma forma atenuada de dualismo de propriedades é a idéia de que as propriedades mentais estão fortemente conectadas às propriedades físicas, de modo que aquelas não podem existir sem estas. Isso faz das propriedades mentais, apesar de sua irredutibilidade às propriedades que são físicas em sentido estrito (aquelas descritas pelas ciências naturais básicas), um tipo de propriedades "físicas" em sentido amplo (pois elas não poderiam ser instanciadas independentemente da instanciação de certas propriedades físicas). A relação entre as propriedades mentais e físicas segundo o fisicalismo nãoredutivo pode ser pensada de diversas maneiras, mas a mais difundida ao longo das últimas décadas tem sido a superveniência ${ }^{13}$, um tipo de relação que Searle admite, em certo sentido, para explicar a conexão entre mente e corpo. ${ }^{14}$ A superveniência seria uma relação entre famílias de propriedades (p. ex. as propriedades de tipo A e as de tipo B) na qual não haveriam situações possíveis idênticas nas propriedades de tipo A mas diferentes nas propriedades de tipo B (cf. Chalmers 1996, p.33). ${ }^{15}$

Cabe então investigar se a teoria de Searle mantém um dualismo de propriedades suficientemente moderado, compatível com a tese de que as propriedades mentais 
dependem das propriedades físicas (de modo que o domínio físico se mostra como o domínio mais fundamental do universo - a tese do fisicalismo) ${ }^{16}$, ou se ele adere a um dualismo de propriedades extremado, que defende a existência de um domínio de propriedades acima e além (over and above) das propriedades físicas, um domínio de propriedades mentais que poderiam, em princípio, existir sem estas últimas.

Para esclarecer essas duas possibilidades interpretativas, viabilizando uma escolha entre elas, será seguido o seguinte percurso: em primeiro lugar (seção 2), serão examinadas as teses fundamentais da teoria de Searle que a aproximam do fisicalismo, a saber, as teses (2), (3) e (4) apresentadas acima. Em seguida (seção 3), será examinada a maneira como a argumentação que ele usa para fundamentar a tese da irredutibilidade ontológica — tese (1) — se assemelha à principal argumentação dos dualistas, baseada na subjetividade da consciência fenomenológica (no aspecto qualitativo da experiência consciente). Por fim (seção 4), será discutido o modo como Searle (apesar de defender um fisicalismo a respeito dos particulares) aceita essa argumentação dos dualistas contemporâneos a favor da diferença ontológica entre o mental e o físico. O resultado é que, na falta de uma explicação satisfatória de como os fenômenos mentais (ontologicamente subjetivos e, portanto, irredutíveis) poderiam fazer parte da realidade física, a interpretação mais plausível é a de que o naturalismo biológico não é uma teoria suficientemente fisicalista, mas sim um dualismo de propriedades radical.

\section{Pontos de contato com o fisicalismo}

Searle admite que o problema mente-corpo não é, na verdade, um problema único, mas sim um conjunto de diversos problemas (cf. 1983, p.264 [366]), porém, entre eles um teria uma posição de destaque: o problema da causação mental. É interessante notar que o importante filósofo alemão Peter Bieri (que também afirma a multiplicidade dos problemas mente-corpo), caracteriza o problema mais tradicional em termos da incompatibilidade entre $\left(1^{*}\right)$ a diferença ontológica entre mente e corpo, $\left(2^{*}\right)$ a eficácia causal da mente e $\left(3^{*}\right)$ o fechamento causal do mundo físico (cf. 1981, p.5). ${ }^{17}$

Nesse sentido, a tese (4) do naturalismo biológico significa uma rejeição ao epifenomenalismo (a visão segundo a qual os fenômenos mentais são um subproduto causalmente inerte da atividade cerebral), ou seja, significa uma adesão à tese $\left(2^{*}\right)$ formulada por Bieri. Uma vez que ele também adere à tese $\left(3^{*}\right)$, a solução de Searle para o problema da causação mental é refutar a tese $\left(1^{*}\right)$ - cf. Searle 2004, p.207 refutação que tem de ser interpretada, no meu modo de entender, como a defesa de alguma forma de fisicalismo. ${ }^{18}$ Pelo fato de os fenômenos mentais serem fenômenos biológicos - que são um tipo de fenômenos físicos — não há problema em se aceitar que eles causam outros fenômenos biológicos. ${ }^{19}$ 
E a maneira como os fenômenos mentais pertencem ao domínio físico é explicada, na visão de Searle, pelas teses (2) e (3). ${ }^{20}$ Ele apresenta explicitamente essas teses (da relação causal e da relação de ser uma propriedade do sistema) como explicativas da relação entre o mental e o físico, isto é, como teses que explicam a ontologia (o modo de existência) da mente no mundo dos fenômenos físicos. Em virtude do objetivo do presente trabalho - determinar se o naturalismo biológico é um fisicalismo não-redutivo (dualismo moderado) ou um dualismo de propriedades (um anti-reducionismo radical) - irei discutir essas teses a partir de uma perspectiva determinada: procurarei mostrar como Searle as formula de maneira a alicerçar um fisicalismo brando, compatível com a irredutibilidade da mente. ${ }^{21}$ Em uma interessante passagem, Searle descreve as relações de causação e de realização da seguinte maneira:

O primeiro passo na solução do problema mente-corpo é: processos cerebrais causam processos conscientes. Isso nos deixa com a seguinte questão: qual é a ontologia, qual é a forma de existência desses processos conscientes? Ou, mais precisamente, a afirmação de que há uma relação causal entre o cérebro e a consciência nos compromete com um dualismo de coisas "físicas" e coisas "mentais"? A resposta é definitivamente não. Os processos cerebrais causam a consciência, mas a consciência que eles causam não é uma substância ou entidade extra [grifo meu]. É apenas uma característica de nível superior de todo o sistema. (Searle 2002a, p.9 [4-5])

Em primeiro lugar, ele afirma a relação causal entre processos cerebrais e processos conscientes e imediatamente reconhece que o conceito de "causação" implica numa certa contingência do vínculo entre mente e cérebro, contingência que poderia chegar ao extremo do dualismo ontológico ("trata-se de uma relação causal entre fenômenos essencialmente diversos" - diria um dualista). ${ }^{22}$ Porém, essa posição extrema poderia ser evitada através do conceito de "realização" (ser uma propriedade realizada no nível do sistema), pois a propriedade realizada por um sistema físico teria de ser uma propriedade, em certo sentido, física.

Mas é crucial perceber que a relação de ser uma propriedade do sistema (ao mesmo tempo em que garante um certo compromisso com o fisicalismo) pode ser interpretada de tal modo que ela implique uma não-identidade entre fenômenos mentais e processos cerebrais, pois se um dado fenômeno mental é uma propriedade do sistema cerebral (e não de cada um de seus elementos isoladamente), então trata-se de uma propriedade diferente das propriedades dos neurônios (os elementos básicos do sistema cerebral), por mais que esteja estreitamente vinculada a estas últimas.

Portanto, o emprego do conceito de "realização" por Searle é mais um indício de que ele pensa o naturalismo biológico como uma forma de fisicalismo não-redutivo (por mais que a noção de realização em Searle seja relativamente pobre) ${ }^{23}$, pois 
uma vez que as propriedades do sistema se distinguem das propriedades de seus elementos, as propriedades sistêmicas conscientes não poderiam ser identificadas com propriedades neuronais em sentido estrito (é nesse sentido que Searle procura alicerçar um fisicalismo brando, distanciado da redução das propriedades conscientes às propriedades neuronais).

É interessante notar que se o conceito de "realização" articulado por Searle está estreitamente vinculado à noção de "propriedade sistêmica", isso também se aplica a um outro conceito empregado por ele para explicar a relação entre mente e corpo: o conceito de propriedade emergente. Em escritos mais antigos a respeito do problema mente-corpo, Searle se refere à consciência como uma "propriedade emergente" do sistema cerebral (cf. 1992, p.14 [29]). Em A redescoberta da mente, ele caracteriza tais propriedades como um caso especial de propriedades sistêmicas. No âmbito mais geral haveriam as propriedades que pertencem a determinados sistemas e não a seus constituintes e, em âmbitos mais específicos, haveriam, por um lado, as propriedades do sistema que podem ser deduzidas ou calculadas a partir das propriedades dos seus elementos constituintes e, por outro lado, as propriedades sistêmicas que tem de ser explicadas em termos das interações causais entre os elementos constituintes do sistema em questão, que ele denomina propriedades causalmente emergentes (cf. 1992, p.111 [161-2]). ${ }^{24}$

Essa distinção entre dois tipos de propriedades sistêmicas proposta por Searle parece claramente corresponder à distinção feita pelos emergentistas britânicos ${ }^{25}$ entre propriedades "resultantes" e "emergentes". No primeiro caso, temos propriedades de um todo que surgem por simples adição ou subtração das propriedades de suas partes (como p. ex. o peso de uma mesa é simplesmente a soma dos pesos de suas partes) ao passo que, no segundo caso, temos propriedades que só são instanciadas quando os elementos do sistema entram em uma relação apropriada, e que não poderiam ser previstas a partir das propriedades dos elementos antes de sua efetiva instanciação pelo todo. ${ }^{26}$

A consciência - enquanto uma propriedade causalmente emergente do sistema cerebral - é, conforme a tese (1), ontologicamente irredutível aos processos no micronível do sistema, o que mostra a adesão de Searle à concepção emergentista segundo a qual os fenômenos emergentes são irredutíveis (cf. Kim 1996, p.228; Kim 1992, p.123). ${ }^{27}$ Porém, é importante perceber que Searle pensa sua noção de propriedade emergente como compatível com a redução causal. Ele distingue entre propriedades emergentes de tipo 1, que tem de ser explicadas em termos das interações causais entre os elementos do sistema, e propriedades emergentes de tipo 2, que possuiriam capacidades causais que não podem ser explicadas em termos das interações causais entre os elementos, mas acredita que a consciência não é uma propriedade emergente de tipo 2 (cf. 1992, p.112 [162-3]). ${ }^{28} \mathrm{Na}$ verdade, mais do que considerar sua noção de propriedade emergente compatível com a redutibili- 
dade causal, Searle acredita haver um vínculo entre redução causal e emergência: "O princípio geral em tais casos parecer ser este: quando se percebe que uma propriedade é emergente 1, automaticamente obtemos uma redução causal" (Searle 1992, p.116 [167]).

Em outras palavras, certas propriedades sistêmicas (como transparência, liquidez ou consciência) são instanciadas quando os elementos de um sistema estão nas relações causais adequadas, de maneira que tais propriedades emergentes seriam causalmente redutíveis às interações entre os elementos do sistema (ainda que sejam ontologicamente irredutíveis). Isso significa que uma propriedade emergente, como a consciência, é (a) causalmente explicável em termos das interações causais no micronível; e (b) tem as mesmas capacidades causais dos elementos do sistema em interação (cf. Searle 2002b, p.60). Essas condições da redução causal estão de acordo com a ideia dos emergentistas, segundo a qual as propriedades emergentes estão nomologicamente conectadas com as propriedades dos elementos do sistema. Segundo Kim:

O emergentista não teria tido nenhum problema com leis conectando propriedades emergentes com suas bases subjacentes no nível inferior. Na verdade eles estão comprometidos com a existência de tais leis: quando as "condições basais" apropriadas estão presentes, as propriedades emergentes tem necessariamente de emergir. Quando as mesmas condições basais ocorrem de novo, temos todas as razões para esperar o aparecimento da mesma propriedade emergente. (1996, p.228, grifado no original)

A condição (a) - explanabilidade causal - é claramente concebida por Searle em termos da constatação de leis causais ${ }^{29}$, do mesmo modo que a condição (b) - a identidade das capacidades causais - está ligada à estreita correlação entre as propriedades micro e macro (cf. por exemplo Searle 1980, p.455 - citado na nota 3 do presente trabalho), correlação que Searle concebe como fundada em leis causais (cf. Prata 2008b, p.9-13). Mas não se pode esquecer que a conexão entre a consciência e a atividade cerebral por meio de leis psicofísicas é pensada por ele como compatível com a irredutibilidade ontológica, pois, apesar dessa conexão, as propriedades subjetivas (que formam a consciência) não poderiam ser descritas em termos objetivos (p. ex. os do vocabulário neurobiológico):

O sentido no qual, embora causalmente redutível, [a consciência] é ontologicamente irredutível é que uma descrição completa das características objetivas, de terceira pessoa, do cérebro não seria uma descrição de suas características subjetivas de primeira pessoa. (Searle 2002b, p.61)

O uso do conceito de emergência no naturalismo biológico deve ser contado entre as evidências de que essa teoria é concebida como uma forma de fisicalismo anti-reducionista, pois, como coloca Kim, o emergentismo do início do século XX 
"foi a primeira formulação sistemática do fisicalismo não-redutivo" (1996, p.226; cf. também, Kim 1992, p.128). Porém, como será exposto a seguir, o naturalismo biológico de Searle inclui teses que o aproximam de um dualismo de propriedades mais radical.

\section{Pontos de contato com o dualismo de propriedades}

Em exposições recentes do seu naturalismo biológico, Searle coloca como a primeira tese básica de sua teoria um realismo a respeito da mente, que decorre da ideia de que os fenômenos mentais conscientes possuem um modo de existência (isto é, uma ontologia) peculiar, que os tornam ontologicamente irredutíveis a qualquer outro tipo de fenômeno (cf. Searle 2004, p.113; 2007, p.170). A questão é que essa irredutibilidade é, sem sombra de dúvida, concebida por ele em termos de uma independência conceitual dos fenômenos mentais em relação aos fenômenos físicos, o que parece completamente incompatível com um fisicalismo aceitável, pois tal independência implica que se possa conceber, por exemplo, sistemas fisicamente idênticos a um ser humano, mas sem consciência, indicando que se tratam de entidades de tipo diferente.

Segundo ele, todo estado mental consciente tem um aspecto qualitativo, isto é, um modo como nós o sentimos, quando nos encontramos nesse estado (cf. Searle 2004, p.134), e nenhuma descrição dos fenômenos objetivos (processos cerebrais) que subjazem a tal estado seria capaz de expressar o aspecto qualitativo, que é subjetivo (cf. Searle 2002b, p.61), pois esses dois tipos de fenômenos são essencialmente diversos (cf. Searle 1992, p.117 [170]). Isso leva, de acordo com o próprio Searle, a uma situação na qual a presença de estados de consciência sem qualquer substrato físico permanece concebível, embora não se sustente como hipótese científica (cf. Searle 2004, p.43).

Por um lado, dizer que a existência de fenômenos mentais sem a existência de fenômenos físicos não é viável como hipótese científica, sugere que há uma correlação empírica entre o mental e o físico, de modo que no nosso mundo, com as leis naturais vigentes nele, determinados fenômenos mentais existem correlacionados a determinados fenômenos físicos. Por outro lado, dizer que a existência de fenômenos mentais sem a existência de fenômenos físicos é logicamente concebível, abre margem para o dualismo ontológico ${ }^{30}$, isto é, abre margem para a ideia de que os fenômenos mentais não pertencem necessariamente à estrutura do universo físico, mas sim são algo adicional, atrelado de modo contingente aos fenômenos físicos (existindo de um modo diverso). ${ }^{31}$

A ideia de que fenômenos mentais estão correlacionados a certos fenômenos físicos em virtude das leis naturais vigentes no nosso mundo, conduz à assunção de

Principia 16(2): 255-276 (2012). 
que tal vínculo é contingente, pois, de acordo com Lange (2008, p.203), o ponto de vista padrão a respeito das leis da natureza distingue entre (a) necessidades lógicas ou metafísicas, por um lado, e (b) fatos contingentes, por outro, sendo que essa segunda categoria abrangeria tanto $\left(\mathrm{b}_{1}\right)$ as necessidades nomológicas, decorrentes das leis naturais, quanto $\left(\mathrm{b}_{2}\right)$ os fatos acidentais. Uma lei da natureza seria um fato "contingente" no sentido de que a sua necessidade é mais fraca do que a necessidade lógica ou metafísica (cf. 2008, p.204), de tal modo que seriam concebíveis situações nas quais essa lei não se aplicasse. Assim, se os fenômenos mentais estão conectados a certos fenômenos físicos por meras leis naturais (nomologicamente necessárias, mas metafisicamente contingentes), podemos conceber situações contrafactuais em que um sistema físico não possui propriedades mentais, indicando que os dois domínios existem de modos diversos.

É interessante notar que a possibilidade conceitual de conceber o físico e o mental como domínios independentes, que Searle reiteradamente aceita é, historicamente, o principal argumento para o dualismo, seja de substâncias ou de propriedades. $\mathrm{O}$ argumento de Descartes para a diferença real entre a alma e o corpo se baseia na possibilidade de se conceber clara e distintamente um sem o outro. Após formar, na segunda de suas Meditações metafísicas, uma concepção clara e distinta da alma como coisa pensante (com base no argumento de que podia duvidar que tinha um corpo, mas não que pensava); após provar, na quarta meditação, que tudo o que é concebido com clareza e distinção é verdadeiro, tal como foi concebido; e após formar, parte na segunda, parte na quinta e parte na sexta meditação, uma concepção clara e distinta das coisas corporais; Descartes se sente autorizado a concluir que "as coisas que se concebe clara e distintamente serem substâncias diferentes, como se concebe o espírito e o corpo, são, com efeito, substâncias diversas, e realmente distintas umas das outras" (1979, p.79-80 [AT, IX, 10]). ${ }^{32}$

Essa linha de argumentação foi retomada no século XX por importantes filósofos como Saul Kripke, Thomas Nagel, Frank Jackson e Chalmers. Este último, provavelmente o mais influente na atualidade, reconhece Descartes como um precursor do argumento de que seria logicamente possível um sistema físico idêntico a um ser consciente, mas que não possui consciência (cf. Chalmers 2003, p.135, nota de rodapé $\mathrm{n}^{\mathrm{0}}$ 6). ${ }^{33}$ Searle oferece uma formulação geral do argumento indicando que, dada qualquer versão do fisicalismo (teoria da identidade, funcionalismo, etc.), é possível imaginar uma circunstância na qual todos os predicados físicos são satisfeitos sem que nenhum predicado mental o seja, isto é, seria possível imaginar um ser que "se parecesse e se comportasse exatamente como eu, mas fosse inconsciente. Este é algumas vezes chamado o 'argumento do zumbi', porque seria possível que existissem zumbis que se comportassem exatamente como eu, mas sem características mentais" (Searle 2007, p.177). Chalmers, formula sua versão própria do argumento nos seguintes termos (1996, p.123): 
$\left(1^{\prime}\right)$ No nosso mundo, existem experiências conscientes.

$\left(2^{\prime}\right)$ Existe um mundo logicamente possível que é fisicamente idêntico ao nosso, no qual os fatos positivos sobre a consciência em nosso mundo não tem lugar.

$\left(3^{\prime}\right)$ Portanto, fatos sobre a consciência são fatos adicionais acerca do nosso mundo, acima e além dos fatos físicos.

(4') Logo, o materialismo é falso.

Como esclarece Searle, os dualistas pretendem, com argumentos desse tipo, indicar uma diferença entre o mental e o físico, na medida em que, por um lado, seria logicamente possível que o universo fosse exatamente como ele é, átomo por átomo, sem consciência, ao passo que, por outro lado, não é logicamente possível que o universo fosse exatamente como ele é, átomo por átomo, sem que suas propriedades físicas fossem exatamente como elas são (cf. Searle 2004, p.128). Isso indicaria que a consciência é essencialmente diferente das propriedades físicas.

É exatamente aquele tipo de argumento que Searle utiliza para defender a irredutibilidade ontológica da consciência. Em A redescoberta da mente, Searle afirma que Kripke, Nagel e Jackson defenderam diferentes versões do mesmo argumento contra o reducionismo em filosofia da mente, argumento que ele formula, tomando o exemplo da sensação de dor, da seguinte maneira: "nenhuma descrição dos fatos de terceira pessoa, objetivos, fisiológicos, iria expressar o caráter subjetivo, de primeira pessoa, da dor, simplesmente porque as características de primeira pessoa são diferentes das características de terceira pessoa" (Searle 1992, p.117 [170]).

Essa impossibilidade, afirmada por Searle, de se expressar o caráter subjetivo através de descrições objetivas implica a possibilidade lógica de se conceber um sistema dotado da mesma complexidade física, química e biológica que nosso corpo, mas que não instancia quaisquer propriedades mentais; o que, para os dualistas de propriedades, indica que estas estão, de certo modo, acima e além das propriedades físicas do sistema em seus diversos níveis (atômico, molecular, celular, etc.). Sendo assim, colocando as coisas nos termos usados por Searle, no caso de sistemas biológicos complexos, dotados de um aparato neurológico adequado, haveria, além das propriedades físicas e biológicas comuns, um conjunto de propriedades essencialmente diferentes, que só existem na medida em que são experienciadas (cf. Searle 2002a, p.41 [59]), as propriedades ontologicamente subjetivas.

O que é curioso a respeito de Searle é que, ao mesmo tempo em que ele aceita alegremente essa linha de argumentação (anti-fisicalista) contra o reducionismo, ${ }^{34}$ ele pretende rejeitar o dualismo de propriedades. Em $A$ redescoberta da mente ele nega que a irredutibilidade tenha "conseqüências metafísicas profundas" (1992, p.122 [177]), ${ }^{35}$ e há dez anos ele publicou um artigo com o objetivo de rechaçar a interpretação de sua teoria como um dualismo de propriedades (cf. Searle 
2002b). ${ }^{36}$ mas suas alegações são intensamente discutidas na literatura (cf. NidaRümelin 2002, p.218-20; Feser 2004).

Em escritos mais recentes (cf. Searle 2004, p.129; 2007, p.177) Searle argumenta contra o dualismo afirmando que apesar da possibilidade lógica de se conceber um mundo físico como o nosso desprovido de consciência, tal mundo não é efetivamente possível. Se ele fosse bem sucedido nessa sua argumentação, então seria possível conciliar a irredutibilidade das propriedades subjetivas com o caráter ontológico fundamental do domínio físico, isto é, conciliar o anti-reducionismo a respeito da mente com um monismo ontológico fisicalista.

Porém, penso que o argumento de Searle se mostra ineficaz, e sua aceitação de um anti-reducionismo tão forte, quanto o que foi exposto acima, torna inevitável a conclusão de que a teoria é um dualismo de propriedades. Cabe agora examinar porque os argumentos expostos em Searle (2004, p.129) e (2007, p.177) fracassam.

\section{Os argumentos contra o dualismo ontológico}

Em consonância com a linha de argumentação contra o reducionismo exposta acima, Searle afirma que "o argumento [da possibilidade lógica] é correto em destacar que uma descrição de fatos de terceira pessoa não implica a existência de fatos de primeira pessoa, e isso pela razão trivial de que a ontologia de primeira pessoa não pode ser reduzida à ontologia de terceira pessoa" (Searle 2004, p.129, grifo meu). Entretanto, apesar de concordar com os defensores do argumento da possibilidade lógica, no sentido de que este argumento demonstraria a independência conceitual entre o mental e o físico, Searle acha precipitado concluir a verdade de um dualismo ontológico - "eu mesmo usei uma versão mais fraca e cautelosa desse argumento" (Searle 2007, p.177) —, pois as leis da natureza inviabilizariam essa conclusão. No seu livro Mind: a Brief Introduction, Searle argumenta da seguinte maneira:

\footnotetext{
Quando imaginamos a trajetória das micropartículas, nós estávamos considerando todas as leis da natureza constantes. Se nós tentamos imaginar a trajetória das micropartículas sendo a mesma, mas sem a consciência então estamos trapaceando no experimento de pensamento, porque não estamos imaginando as micropartículas se comportando precisamente da mesma maneira que elas iriam se comportar se elas estivessem agindo de acordo com todas as leis da natureza, i.e., de tal modo que elas causam e realizam estados conscientes (subjetivos, de primeira pessoa). Desde que as leis da natureza sejam incluídas na descrição do universo físico, e elas tem que ser incluídas porque elas são parcialmente constitutivas do universo físico, então a existência da consciência se segue, como uma consequência lógica daquelas leis. (Searle 2004, p.129)
}

Principia 16(2): 255-276 (2012). 
A ideia de Searle parece ser a seguinte: entre as leis da natureza se encontram leis psicofísicas, isto é, leis em decorrência das quais determinados processos cerebrais causam determinados fenômenos mentais conscientes. Quando concebemos o universo permanecendo fisicamente idêntico, mas sem a consciência, não estamos, de fato, concebendo-o exatamente como ele é, pois estamos deixando de lado essas leis psicofísicas. Se as levamos em consideração, então não pode existir um universo fisicamente igual ao nosso, mas sem fenômenos conscientes, pois a existência de tais fenômenos seria uma consequência "lógica" das leis naturais psicofísicas. ${ }^{37}$

Essa linha de argumentação é muito estranha, porque parece atribuir às leis da natureza uma necessidade muito mais forte do que (diante de uma reflexão mais cuidadosa) elas de fato possuem: por mais que uma determinada lei psicofísica tenha vigência em nosso mundo (atual), de modo que ela torne necessário o vínculo entre certos processos cerebrais e certos fenômenos conscientes, é muito difícil aceitar que se trate aqui de uma necessidade "lógica", pois sempre podemos conceber outros mundos (possíveis) nos quais essa lei não tem vigência. Um argumento para esta última afirmação pode ser extraído das seguintes considerações de Chalmers:
A pressão exercida por um mol de gás depende sistematicamente de sua temperatura e volume de acordo com a lei $p V=K T$, onde $K$ é uma cons- tante. [...] No mundo atual, onde quer que exista um mol de gás com uma dada temperatura e volume, sua pressão estará determinada: é empirica- mente impossível que dois moles de gás distintos tenham a mesma tempe- ratura e volume, mas uma pressão diferente. [...] [Porém] é logicamente possível que um mol de gás com uma dada temperatura e volume possa ter uma pressão diferente; imagine um mundo no qual a constante $K$ é maior ou menor, por exemplo. Na verdade, é apenas um fato da natureza que exista essa correlação (Chalmers 1996, p.36).

Esse exemplo evidencia porque os mundos possíveis de acordo com as leis da natureza formam um subconjunto bastante restrito do conjunto dos mundos conceitualmente possíveis. Mesmo se consideramos uma dada lei natural (como p. ex. $p V=K T$ ), podemos conceber situações contrafactuais nas quais ela varia (como no caso da variação do valor da constante $K$ ), ou simplesmente não vale, evidenciando sua contingência (cf. Lange 2008, p.204). E me parece que uma lei psicofísica, conectando um determinado processo cerebral com um determinado quale (aspecto qualitativo específico, p. ex., o modo como vejo a cor vermelha), teria um alto grau de contingência, assim como tem a constante $K$ citada por Chalmers. Se é assim, mesmo levando em consideração as leis psicofísicas, poderíamos ainda conceber situações logicamente possíveis onde um determinado processo cerebral causasse um quale (aspecto qualitativo) diverso daquele que ele causa no mundo atual.

Mas é necessário, ainda, examinar em mais detalhes as considerações de Searle a respeito das leis naturais, pois ele tenta colocar de modo um pouco mais preciso 
a maneira como elas, na visão dele, inviabilizariam a existência de propriedades subjetivas desvinculadas de propriedades objetivas. Rejeitando tal dualismo entre propriedades, Searle afirma:
A imagem que os dualistas tem é que as micropartículas são como minúscu- los grãos de areia afetados por forças independentes, e eles podem imaginar o movimento da areia sem nenhuma consciência. Mas essa é uma imagem falsa. No nível mais fundamental, pontos de massa/energia são constituídos por forças, que são descritas pelas leis da natureza. E dessas leis a existência da consciência se segue como uma consequência lógica, exatamente como a existência de qualquer outro fenômeno biológico, tais como crescimento, digestão ou reprodução (Searle 2004, p.130).

Segundo a visão errônea, as leis naturais seriam algo que se acrescenta às micropartículas. Mas, na realidade, "satisfazer as leis é parcialmente constitutivo das partículas" (Searle 2007, p.177). Searle afirma de modo explícito que as leis da natureza são essenciais à constituição das coisas em nosso universo, afirmação que parece atribuir uma necessidade metafísica às leis da natureza. Ele usa a imagem da criação divina do mundo para explicitar seu ponto de vista: "Deus não cria primeiro os elétrons e depois decide dar a eles uma carga negativa, na verdade, a carga negativa é parte da essência de ser um elétron" (Searle 2007, p.177). Da mesma forma, as leis psicofísicas seriam essenciais à constituição dos sistemas físicos, de modo que a consciência seria uma propriedade física ou, mais exatamente, biológica, como tantas outras.

Essas colocações de Searle permitem situá-lo no panorama do debate filosófico sobre as leis naturais. De acordo com Harré (2001, p.214), ao longo da história, esse debate foi travado entre três grandes correntes: (a) os que veem a necessidade das leis da natureza como um assunto conceitual (p. ex. Aristóteles); (b) os que veem essas leis como sumários da experiência, de modo que a aparente necessidade é fruto de um mero hábito (p. ex. Hume) e (c) os que veem as leis como descrições de poderes naturais (uma visão que teria se articulado na contemporaneidade). As colocações expostas acima (Searle 2004, p.129-30; 2007, p.177) indicam que Searle se integra a esta terceira corrente, cujos membros costumam analisar a necessidade das leis naturais "em termos das essências reais das coisas e substâncias materiais" (Harré 2001, p.215), essências que seriam responsáveis pelos poderes que essas coisas manifestam em situações concretas.

Mas é crucial perceber que os defensores dessa concepção sobre as leis da natureza (como descrições de poderes e tendências naturais), admitem a diferença entre necessidade lógica (decorrente das relações entre simples conceitos) e necessidade nomológica (decorrente das leis naturais), pois se este último tipo de necessidade surge a partir da essência real de uma coisa física, permanece concebível que esta coisa estivesse constituída de outro modo (isto é, tivesse uma essência diferente), 
de forma que uma lei da natureza do mundo efetivo não tem validade em qualquer mundo possível.

A necessidade natural costuma ser vista como decorrente dos mecanismos pelos quais as coisas se estruturam através de diferentes níveis de organização - e esta ideia de "níveis" é mais um indício de que Searle adere a esse modo de ver as leis da natureza (cf. Searle 1992, p.86; 1995, p.217-8). Como exemplifica Harré (2001, p.220): "temos razão para pensar não somente que o carbono reduz o óxido de mercúrio, mas que isso tem que ser assim, dadas as estruturas moleculares e processos que ocorrem na reação". De acordo com o autor, a crença na necessidade (natural) de uma lei, em cada nível de organização, está baseada em nossas crenças sobre a natureza dos mecanismos causais operantes nos níveis mais básicos. Como deixa claro um outro exemplo dado por ele:

Nós explicamos a tendência do sódio de reagir com a água fazendo referência à sua arquitetura eletrônica, e ao mesmo tempo nós definimos o sódio por essa mesma arquitetura. Podemos ver agora como a hierarquia [de níveis] e a necessidade estão ligadas. O sódio tem que reagir com a água (tudo mais sendo constante) porque se esta porção de material não reage, então não é sódio: isto é, não tem aquela arquitetura eletrônica da qual depende sua tendência natural de reagir com a água. (Harré 2001, p.220)

E o ponto decisivo para a discussão do naturalismo biológico é que esse tipo de necessidade não se identifica com a necessidade lógica, uma vez que "é concebível que o sódio, tal como especificado apenas por seu comportamento, pudesse ter tido uma arquitetura diferente" (2001, p.220). Se fosse esse o caso, sua essência seria outra, ${ }^{38}$ e as leis naturais decorrentes dessa essência seriam diferentes das leis naturais vigentes no mundo atual.

Portanto, estamos de volta ao mesmo ponto no qual nos encontrávamos acima, quando eram discutidas algumas considerações de Chalmers sobre a necessidade natural (cf. Chalmers 1996, p.36): a necessidade das leis da natureza no mundo atual não é uma necessidade lógica, o tipo de necessidade invocado por Searle para diferenciar a sua teoria da mente de um dualismo de propriedades. É importante ressaltar que não é o propósito do presente trabalho defender o argumento da possibilidade lógica contra o fisicalismo. A questão aqui é que Searle, explicitamente, aceita o argumento, e conclui a partir dele uma diferença ontológica entre consciência e atividade cerebral (a primeira ontologicamente subjetiva, os últimos ontologicamente objetivos) e, mesmo assim, pretende escapar do dualismo ontológico. Mas o modo como ele pretende escapar desse dualismo, atribuindo uma necessidade lógica às leis naturais, além de arbitrário, é completamente insuficiente, porque o seu recurso às essências das coisas físicas não é capaz de alcançar esse tipo de necessidade, que é, claramente, o que ele ambiciona para poder distanciar sua teoria do dualismo (cf. Searle 2004, p.129-30). 
Ao contrário do que defende Searle, parece claro que, se refletimos sobre fatos do mundo atual (o mundo efetivamente existente), podemos conceber mundos alternativos, com base apenas em nossos conceitos, que não são empiricamente possíveis (porque eles violam as leis da natureza), e podemos concebê-los, justamente, porque as leis naturais dão margem a essa concepção de nossa parte. Nesse sentido, podemos falar de mundos que são possíveis segundo as leis da natureza do mundo atual - por exemplo, uma situação na qual o planeta terra fosse completamente desprovido de biosfera —, e de mundos que, apesar de nomologicamente impossíveis, são possíveis conceitualmente (pois não são contraditórios) — por exemplo, um mundo no qual blocos de granito flutuam sobre a água. Mesmo que uma lei da natureza tenha vigência no mundo atual, de modo a determinar uma larga série de mundos possíveis, tal lei não tem vigência em todos os mundos logicamente possíveis. Já que podemos conceber inúmeras variações a partir do que é efetivamente o caso, os mundos conceitualmente possíveis formam um conjunto mais amplo do que o dos mundos possíveis segundo as leis naturais. ${ }^{39}$

Mas se são concebíveis situações nas quais, por exemplo, um determinado processo cerebral causasse um fenômeno consciente com um outro aspecto qualitativo (diferente daquele que ele tem no mundo atual), então isso significa que a conexão entre as propriedades objetivas que compõem o processo cerebral (descritíveis no vocabulário da física, da química e da biologia) e as propriedades subjetivas dos fenômenos mentais conscientes (descritíveis no vocabulário fenomenológico das sensações e percepções) é uma conexão contingente, indicando que os fenômenos subjetivos formam um domínio que está "acima e além" do domínio dos fenômenos objetivos. Portanto, uma vez que sua teoria leva a uma tal contingência da relação entre mente e cérebro, Searle se alinha, sem dúvida, ao dualismo de propriedades. ${ }^{40}$

\section{Referências}

Beckermann, A.; Flohr, H.; Kim, J. (eds.) 1992. Emergence or reduction? Essays on the Prospects of Nonreductive Physicalism. Berlin, Nova Iorque: De Gruyter.

Beckermann, A. 1992a. Introduction - Reductive and Nonreductive Physicalism. In: Beckermann et al. 1992, p.1-21.

— 1992b. Supervenience, Emergence, and Reduction. In: Beckermann et al. 1992, p.94-118.

- 2001. Analytische Einführung in die Philosophie des Geistes. Berlin, New York: Walter de Gruyter.

Bermúdez, J. L. 2005. Philosophy of Psychology: a Contemporary Introduction. Nova Ioque; Londres: Routledge.

Bieri, P. 1981. Generelle Einführung. In: Bieri, P. (ed.) Analytische Philosophie des Geistes. Königstein: Verlag Anton Hain, p.1-28.

Principia 16(2): 255-276 (2012). 
Block, N. 1980. Introduction: What Is Functionalism? In: Block, N. (ed.) Readings in the Philosophy of Psychology. Cambridge (Mass.): Harvard University Press, p.171-84.

Chalmers, D. 1996. The Conscious Mind: In Search of a Fundamental Theory. Oxford: Oxford University Press.

- 2003. Consciousness and its Place in Nature. In: Stich, S. P.; Warfield, T. A. (eds.) The Blackwell Guide to the Philosophy of Mind. Malden, Oxford, Melbourne, Berlin: Blackwell Publishing, p.102-42.

Churchland, P. 2004. Matéria e consciência: uma introdução contemporânea à filosofia da mente. São Paulo: Editora da Unesp.

Cunningham, S. 2000. What is a Mind? An Integrative Introduction to the Philosophy of Mind. Indianápolis: Hackett Publishing.

Descartes, R. 1979. Discurso do método; Meditações; Objeções e Respostas; As Paixões da Alma; Cartas. 2- ed. São Paulo: Abril Cultural (Os Pensadores).

—. 1992. Méditations Métaphysiques: Objections et Réponses suivies de quatre lettres. Paris: Flammarion.

Feser, E. 2004. Why Searle Is a Property Dualist. Paper presented at the American Philosophical Association Pacific Division meeting in Pasadena, CA, March 24-28.

Harré, R. 2001. Laws of nature. In: W. H. Newton-Smith (ed.) A Companion to the Philosophy of Science. Oxford: Blackwell, p.213-23.

Heil, J. 2004. Reduction. In: Heil, J. (ed.) Philosophy of Mind: a Guide and Anthology. Oxford: Oxford University Press, p.677-84.

Hodgson, D. 1994. Why Searle has not Rediscovery the Mind. Journal of Consciousness Studies 1(2): 264-74.

Kemmerling, A. 1994. Von der Sprache zum Bewusstsein: John R. Searle löst sich vom analytischen Mainstream. Merkur - deutsche Zeitschrift für europäisches Denken 48(5): 432-8.

Kim, J. 1992. 'Downward Causation' in Emergentism and Nonreductive Physicalism. In: Beckermann et al. 1992, p.119-38.

—. 1993. Supervenience and Mind: Selected Philosophical Essays. Cambridge UK: Cambridge University Press.

- 1994. Supervenience. In: Guttenplan, S. (ed.) A Companion to the Philosophy of Mind. Oxford/Cambridge MA: Basil Blackwell, p.575-83.

Jackson, F. 1982. Epiphenomenal Qualia. Philosophical Quarterly 32: 127-36.

— 1995. Mental Causation in Searle's 'Biological Naturalism'. In: Kim, J.; Jakob, P. et al. Searle Symposium. Philosophy and Phenomenological Research 55(1): 189-94.

- 1996. Philosophy of Mind. Oxford, Boulder: Westview Press.

Kripke, S. 2001. Naming and Necessity. Cambridge (Mass.): Harvard University Press.

Lange, M. 2008. Laws of nature. In: S. Psillos; M. Curd (eds.) The Routledge Companion to Philosophy of Science. London: Routledge, p.203-12.

Maslin, K. T. 2001. An Introduction to the Philosophy of Mind. Cambridge (UK): Polity Press.

- 2009. Filosofia da mente. Porto Alegre: Artmed.

McLaughlin, P. 1993. Descartes on Mind-Body Interaction and the Conservation of Motion. Philosophical Review 102(2): 155-82.

Melnyk, A. 2003. Physicalism. In: Stich, S.; Warfield, T. (eds.) The Blackwell Guide to Philosophy of Mind. Malden, Oxford, Melbourne, Berlin: Blackwell Publishing, p.65-84.

Nagel, T. 1974. What Is It Like To Be a Bat? Philosophical review 83: 435-50.

Principia 16(2): 255-276 (2012). 
Nida-Rümelin, M. 2002. Causal Reduction, Ontological Reduction and First-Person Ontology. Notes on Searle's Views about Consciousness. In: Grewendorf, G.; Meggle, G. (orgs.) Speech Acts, Mind and Social Reality: Discussions with John R. Searle. Dordrecht, Boston, London: Kluwer Academic Publishers, p.205-21.

Place, U. T. 1988. Thirty Years On - Is Consciousness Still a Brain Process? Australasian Journal of Philosophy 66(2): 208-19.

Prata, T. A. 2008a. There can be Causal without Ontological Reducibility of Consciousness? Troubles with Searle's Account of Reduction" Reduction and Elimination in Philosophy and the Sciences: Papers of the 31st International Wittgenstein Symposium. Kirchberg am Wechsel (Áustria): Austrian Ludwig Wittgenstein Society, p.55-7.

- 2008b. Dificuldades da concepção de John Searle sobre a redução da consciência: o problema das capacidades causais. Princípios 15(2): 5-29.

- 2009. Irredutibilidade ontológica versus identidade: John Searle entre o dualismo e o materialismo. O que nos faz Pensar 25: 107-24.

- 2011. É incoerente a concepção de Searle sobre a consciência? In: Manuscrito 34(2): 557-78.

Schröder, J. 1992. Searles Auffassung des Verhältnisses Von Geist und Körper und ihre Beziehung zur Identitätstheorie. Conceptus 26(66): 97-109.

Searle, J. R. 1980. Intrinsic Intentionality. Behavioral and Brain Sciences 3: 450-6.

- 1983. Intentionality: a Essay in the Philosophy of Mind. Cambridge: Cambridge University Press.

—. 1984. Minds, Brains and Science. Cambridge Mass., Harvard University Press.

1995. Intencionalidade. São Paulo: Martins Fontes.

- 1992. The Rediscovery of the Mind. Cambridge Mass., London: MIT Press.

-1997. A redescoberta da mente. São Paulo: Martins Fontes.

- 1994. Searle, John R. In: Guttenplan, S. (ed.) A Companion to the Philosophy of Mind. Oxford/Cambridge MA: Basil Blackwell, p.544-50.

- 1995. Consciousness, the Brain and the Connection Principle: a Reply. Philosophy and Phenomenological Research 55(1): 217-32.

- 2002a. Consciousness and Language. Cambridge (UK): Cambridge U. P.

- 2002b. Why I Am Not a Property Dualist. J. of Consciousness Studies 9(12): 57-64.

- 2004. Mind: a brief introduction. Oxford: Oxford University Press.

- 2007. Dualism Revisited. Journal of Physiology 101: 169-78.

- 2010. Consciência e linguagem. São Paulo: Martins Fontes.

- [s/d.] Mente, cérebro e ciência. Lisboa: Edições 70.

Stephan, A. 1992. Emergence - A Systematic View on its Historical Facets. In: Beckermann et al. 1992, p.25-48.

Stich, S. P. 1987. [Review on Minds, Brains and Science] The Philosophical Review 96: 129-33.

TÁRIK de Athayde Prata Universidade Federal de Pernambuco Centro de Filosofia e Ciências Humanas (15o andar) Departamento de Filosofia Av. Prof. Morais Rego, s/n. Cidade Universitária. 50.740-550 Recife, PE 
BRASIL

tarikbilden@yahoo.de

Resumo. O artigo investiga se o naturalismo biológico (a solução de John Searle para o problema mente-corpo) pode ser considerado uma concepção fisicalista acerca da mente. Apesar de defender um fisicalismo a respeito dos particulares (seção 2), Searle adere ao argumento básico dos dualistas para a irredutibilidade das propriedades mentais (seção 3), e não consegue fundamentar sua alegação de que tal irredutibilidade é compatível com o fisicalismo (seção 4). Desse modo, sua teoria da mente se revela como um dualismo de propriedades.

Palavras-chave: Fisicalismo; possibilidade lógica; dualismo de propriedades.

\section{Notas}

${ }^{1} \mathrm{O}$ primeiro número é o da pagina na edição original. O número entre colchetes é o da pagina da tradução para o português, quando disponível. Nos casos onde não há número entre colchetes, a tradução da citação para o português foi feita pelo autor do presente trabalho.

2 "Dois fenômenos podem estar relacionados tanto pela causação como pela realização, contanto que isso aconteça em níveis de descrição diferentes" (Searle 1983, p.266 [369]).

3 "Estados mentais não são mais epifenomênicos do que a elasticidade e a resistência a perfurações de um pneu de carro cheio são, e as interações podem ser descritas tanto no nível superior quanto no nível inferior, exatamente como no caso análogo do pneu. (grifo meu)" (Searle 1980, p.455). Nessa passagem está sendo sugerida uma identidade entre estados mentais e processos cerebrais subjacentes, análoga à identidade de uma propriedade física (p. ex. elasticidade) com o comportamento da microestrutura. "Objetando contra o que foi dito, alguém poderá dizer que a liquidez, a solidez e assim por diante são idênticas às características da microestrutura. [...] Este pormenor parece-me correto, mas não constitui realmente uma objeção à análise que estou propondo. É uma característica do progresso da ciência que uma expressão que é originalmente definida em termos de características superficiais, acessíveis aos sentidos, seja subsequentemente definida em termos da microestrutura que causa essas características" (1984, p.21 [27], grifo meu). Aqui, Searle reconhece que sua teoria se compromete com esse tipo de identificação e a explica como uma forma de redução definicional (para uma explicação desse tipo de redução, cf. Searle 1992, p.114 [165]).

4 "A consciência tem três aspectos que a fazem diferente de outros fenômenos biológicos e, na verdade, diferente de outros fenômenos no mundo natural" (Searle 2002a, p.39 [56]). "Os estados e processos mentais conscientes têm uma característica especial, não encontrada em outros fenômenos naturais, a saber, a subjetividade" (Searle 1992, p.93 [138], grifo meu).

${ }^{5}$ Em seu primeiro grande livro sobre o problema da consciência, ele afirma: "Aquilo em que quero insistir sem cessar é que podemos aceitar fatos óbvios da física - por exemplo, que o mundo é constituído inteiramente de partículas físicas em campos de força - sem, ao mesmo tempo, negar os fatos óbvios de nossas próprias experiências - por exemplo, que somos todos conscientes e que nossos estados de consciência têm propriedades fenomenológicas irredutíveis bastante específicas" (Searle 1992, p.28 [44-5]).

Principia 16(2): 255-276 (2012). 
${ }^{6}$ Para uma breve discussão das acusações de incoerência ao naturalismo biológico, cf. Prata 2009, p.108-10.

${ }^{7}$ Em um trabalho que está em preparação, abordo esse tema de modo pormenorizado.

${ }^{8}$ S. Cunningham (2000, p.34) caracteriza o fisicalismo não-redutivo como uma "versão fraca de dualismo de propriedades". De acordo com J. Kim (1993, p.340) "o dualismo de propriedades do fisicalismo não-redutivo é um dualismo atenuado: é um dualismo com relações de dependência entre os dois domínios".

${ }^{9} \mathrm{O}$ importante filósofo e cientista cognitivo José Luis Bermúdez considera o dualismo de propriedades defendido por Chalmers como "a mais plausível versão contemporânea do dualismo" (Bermúdez 2005, p.15).

10 "O universo é inteiramente feito de partículas físicas que existem em campos de força e são frequentemente organizadas em sistemas" (Searle 2004, p.126).

${ }^{11}$ Trata-se da concepção que Kim (1993, p.344) denomina monismo físico: "Todos os concretos particulares são físicos". Cf. Kim (1996, p.227): "Tudo o que existe no mundo espaçotemporal são as partículas básicas reconhecidas pela física e seus agregados".

${ }^{12}$ Ou seja, um dualismo de propriedades em conjunção com um fisicalismo a respeito dos particulares é ainda algo muito fraco para os padrões de um fisicalismo aceitável. Nas palavras de Kim (1996, p.221): "Se você quer chamar a si mesmo de 'fisicalista', você provavelmente vai querer ir além do mero fisicalismo ontológico e esclarecer o sentido no qual a teoria física e suas propriedades dão uma descrição do mundo em seu nível mais fundamental". Nessa passagem, "fisicalismo ontológico" equivale ao que ele chamou de "monismo físico" em Kim 1993, p.344.

13 "A resposta mais popular ao longo das últimas duas décadas tem sido que algo é físico em sentido amplo se, e somente se, isso é superveniente a algo físico em sentido estrito" (Melnyk 2003, p.69).

14 "Na explicação que eu tenho proposto, estados mentais são supervenientes a estados neurofisiológicos no seguinte aspecto: causas neurofisiológicas de tipo idêntico teriam efeitos mentalísticos de tipo idêntico" (Searle 1992, p.124). "É certamente verdade que a consciência é superveniente ao cérebro" (Searle 2004, p.148).

${ }^{15}$ Essa é uma noção geral da relação de superveniência, que abrange noções mais específicas. Sobre a distinção entre superveniência local e superveniência global cf. Chalmers 1996, p.334. Sobre a distinção entre superveniência fraca e superveniência forte cf. Beckermann 1992b, p.96-7; Beckermann 2001, p.207; Kim 1993, p.57-67; Kim 1994, p.577-8. A respeito da distinção entre superveniência lógica e superveniência natural cf. Chalmers 1996, p.34-8.

${ }^{16}$ É interessante notar que uma concepção da mente como o funcionalismo, que explica os fenômenos mentais em termos de papéis causais, pode ser considerada uma forma mais branda de dualismo de propriedades, já que papéis causais precisam ser desempenhados por propriedades subjacentes, e propriedades físicas são as candidatas mais plausíveis para desempenhá-los (ou seja, propriedades mentais não poderiam existir na total ausência de propriedades físicas que as realizem).

${ }^{17}$ De acordo com McLaughlin (1993, p.158), essa apresentação do problema mente-corpo formulada por Bieri é a apresentação comumente aceita do problema (McLaughlin escreve "incontroversa").

${ }^{18}$ Vale ressaltar que a causação mental é vista por muitos como um obstáculo insuperável para o fisicalismo não-redutivo (assim como para qualquer dualismo de propriedades). A

Principia 16(2): 255-276 (2012). 
ideia básica é que a diferença ontológica entre propriedades mentais e físicas leva a uma situação na qual certos efeitos possuem duas causas suficientes, o que é absurdo. Comentando esse problema no caso do naturalismo biológico, Jaegwon Kim escreve: "Considere um evento mental, uma instanciação de alguma propriedade mental, $M$. Esse evento, segundo a explicação de Searle, é causado por uma instanciação de certa propriedade biológica, $B$. Vamos assumir que $M$ tem poderes causais, poderes para causar que outras propriedades sejam instanciadas. Podemos distinguir dois casos: (i) a propriedade que $M$ causa é outra propriedade mental; (ii) essa propriedade causada por $M$ é uma proprieade física. (ii) é claramente causação do mental para o físico (chamada de 'causação descendente' em conexão com o emergentismo); (i) pode ser chamada de 'causação de mesmo nível'. Searle, alguém pode presumir, quer ambas. Consideremos primeiramente a possibilidade de (i): uma instanciação de $M$ causa a instanciação de outra propriedade mental $M^{*}$. Temos de lembrar, porém, que, segundo a explicação de Searle, essa instanciação de $M^{*}$, exatamente como a instanciação de $M$, também é causada por algum fenômeno biológico subjacente, a instanciação de alguma propriedade biológica, $B^{*}$. Tudo se parece como se a instanciação de $M^{*}$ em questão tivesse duas causas suficientes distintas, um fenômeno mental $(M)$ e um fenômeno biológico $\left(B^{*}\right)$ ela é causalmente sobredeterminada. É claro que isso se generaliza rapidamente: todos os casos de causação entre fenômenos mentais envolvem a sobredeterminação do efeito." (Kim 1995, p.193). Para um discussão geral a respeito desse problema cf. Heil 2004.

19 "Estados mentais são causados por fenômenos biológicos e causam por sua vez outros fenômenos biológicos. Se alguém quiser um rótulo, pode chamar tal concepção de 'naturalismo biológico.". (Searle 1983, p.264 [366]).

20 "Nós podemos resumir o naturalismo biológico de maneira muito simples em duas proposições: (1) cérebros causam a mente; (2) mentes são características de nível superior do cérebro" (Searle 1994, p.545). Evidentemente, a tese (1) desta citação corresponde à tese (2) formulada na Introdução do presente trabalho, e a tese (2) da citação corresponde à tese (3) no presente trabalho.

${ }^{21}$ Naturalmente, para ser compatível com alguma forma de fisicalismo, a irredutibilidade da mente também teria de ser "branda". Porém, as próximas duas seções do presente trabalho irão mostrar que Searle articula uma irredutibilidade excessivamente forte, que resulta incompatível com o fisicalismo, o que o faz enveredar pelo dualismo de propriedades.

22 Interessante notar que David Chalmers considera que o conceito de "causação" torna a relação entre o mental e o físico contingente: "Como eu, Searle sustenta que a consciência é superveniente de modo meramente natural ao físico. Ele admite que uma réplica zumbi é logicamente possível, sustentando que a consciência é meramente causada por estados do cérebro. Mas ele nega que isso seja uma variedade de dualismo, mesmo de dualismo de propriedades" (1996, p.130).

${ }^{23}$ No funcionalismo enquanto teoria sobre a natureza dos fenômenos mentais (aquilo que Block 1980, p.172, chama de "funcionalismo metafísico") estes fenômenos são concebidos em termos de um papel causal (relações de causa e efeito com elementos do mundo externo e relações com outros fenômenos mentais), e esse papel causal é realizado por fenômenos físicos subjacentes. A relação de realização enquanto o "ser uma propriedade do sistema" é relativamente pobre, porque não é, no caso dos fenômenos mentais, diferente dos casos em que se tratam de fenômenos físicos comuns (como solidez ou liquidez). Dizer que tanto um estado de consciência (subjetivo) quanto o estado sólido de um cubo de gelo (objetivo) são

Principia 16(2): 255-276 (2012). 
propriedades realizadas no sistema é dizer muito pouco.

${ }^{24}$ De acordo com Stephan (1992, p.26-7) a noção de "emergência" foi caracterizada, ao longo do século passado, principalmente em termos de não-aditividade, novidade, imprevisibilidade, e não-dedutibilidade. Na sua caracterização das propriedades causalmente emergentes em 1992, p.111 [161-2], Searle parece ressaltar os aspectos de não-aditividade e nãodedutibilidade, pois ele contrasta as propriedades emergentes com propriedades sistêmicas que podem ser deduzidas, entendidas [figured out] ou calculadas a partir das propriedades de seus elementos.

25 "O emergentismo, que floresceu durante a primeira metade do século XX, foi a primeira formulação sistemática do fisicalismo não-redutivo bem como do modelo multi-estratificado do mundo. Seus principais proponentes incluem não só filósofos acadêmicos como Samuel Alexander, C. D. Broad e A. O. Lovejoy, mas também cientistas de formação como C. Lloyd Morgan" (Kim 1996, p.226).

${ }^{26}$ Beckermann (1992a, p.17) reconstitui a concepção de C. D. Broad sobre as propriedades emergentes da seguinte maneira: "Uma propriedade $F$ de um sistema $S$, feito dos constituintes $C_{1}, \ldots, C_{n}$ que estão na relação $R$, é emergente se e somente se (a) existe uma lei segundo a qual todo sistema com a mesma estrutura [make-up] tem $F$, e se (b) todavia não pode ser provado a partir das leis gerais da ciência natural, que se aplicam a todos os tipos de objetos e não apenas aos objetos como $C_{1}, \ldots, C_{n}$ relacionados pela relação $R$, que sistemas com a mesma estrutura de $S$ tem todas as características (ou exibem exatamente o comportamento) que são típicas da propriedade F" (grifo meu). Se não se pode deduzir a propriedade $F$ a partir das leis gerais da ciência natural, então só se pode constatar a correlação entre a propriedade $F$ e o sistema $S$ (cujos constituintes estão na relação $R$ ) depois que a propriedade $F$ for efetivamente instanciada pelo sistema.

${ }^{27}$ Em agosto de 2004, durante o 26을 Simpósio Internacional Wittgenstein, em Kirchberg (Áustria), Searle declarou ao autor do presente trabalho nunca ter lido os emergentistas britânicos. Sendo assim, provavelmente, ele foi influenciado pelo emergentismo de modo indireto, durante sua permanência em Oxford na década de 1950.

${ }^{28}$ Aliás, Searle não acredita que exista de fato alguma propriedade emergente de tipo 2 : "De fato, não posso pensar em algo que seja emergente 2, e parece improvável que sejamos capazes de descobrir quaisquer características que sejam emergentes 2 , porque a existência de quaisquer características semelhantes pareceria violar até o mais fraco princípio da transitividade da causação" (1992, p.112 [163]).

${ }^{29}$ Ao expor sua concepção sobre a explanação da consciência, Searle sugere um procedimento que consistiria em: "primeiramente, encontrar os eventos neurobiológicos que estão correlacionados com a consciência (os NCC). Em segundo lugar, testar se a correlação é uma relação causal genuína. E, em terceiro lugar, desenvolver uma teoria, idealmente na forma de um conjunto de leis, que formalizariam as relações causais" (Searle 2002a, p.49 [73], grifo meu; cf. Searle 2004, p.146). Portanto, ele afirma explicitamente o vínculo nomológico entre os processos cerebrais e a consciência.

${ }^{30}$ É curioso notar que, na passagem aludida (2004, p.43), Searle está aceitando algo extremamente radical: a possibilidade de uma mente sem corpo. É importante ter em vista que, na contemporaneidade, o argumento contra o fisicalismo é, normalmente, pensado em termos da possibilidade de um sistema físico indistinguível de um ser consciente, mas sem consciência (digamos: um corpo sem mente).

Principia 16(2): 255-276 (2012). 
${ }^{31}$ A diferença entre uma conexão (em algum sentido) necessária ou contingente entre os fenômenos físicos e os fenômenos mentais é o que demarca o dualismo de propriedades "moderado" (fisicalismo não-redutivo) do dualismo de propriedades "extremado".

32 Entre colchetes está a referência da edição de Adam \& Tannery (AT), com volume (do texto em francês, não em latim) em numeral romano e página em numeral arábico. Essa referência é dada no canto de página da edição francesa das meditações consultada para o presente trabalho.

${ }^{33}$ No livro The Conscious Mind, Chalmers afirma: "Eu não sou o primeiro a usar o argumento a partir da possibilidade lógica contra o materialismo. Na verdade, eu penso que de uma forma ou de outra ele é o argumento anti-materialista fundamental na filosofia da mente. [...] Maior atenção tem sido focada nos argumentos anti-materialistas de Jackson (1982) e Kripke (1972)" (1996, p.140). Chalmers avalia (cf. Ibid., p.372) que o argumento é também defendido por Nagel (1974).

${ }^{34}$ Não resta dúvida de que Searle aceita a argumentação de Kripke, Nagel e Jackson: "chega do argumento anti-reducionista. É ridiculamente simples e absolutamente decisivo. Uma enorme quantidade de tinta foi gasta na tentativa de contestá-lo, mas as contestações não passam de tinta jogada fora" (Searle 1992, p.118 [171]).

${ }^{35}$ Para uma crítica do argumento de Searle em A redescoberta da mente, cf. Prata 2008a, p.57.

${ }^{36}$ Para uma discussão das considerações de Searle nesse artigo, cf. Prata 2011, p.573-4.

37 Searle afirma que a possibilidade lógica de um estado de coisas depende do modo como ele é descrito: "É logicamente possível existissem partículas físicas sem qualquer consciência no universo? A resposta é sim. Mas é possível que as trajetórias das partículas físicas ocorressem como elas ocorreram de fato, juntamente com as leis da natureza que (entre muitas outras coisas) determinam que aquelas trajetórias causem e realizem consciência, mas sem nenhuma consciência? A resposta é não. Descrito de um modo, a ausência da consciência é logicamente possível; descrito de outro modo ela não é" (Searle 2004, p.129). Considerando que a diferença entre os dois cenários traçados por Searle são as leis da natureza, e considerando que tais leis não possuem necessidade lógica (cf. Lange 2008, p.204; Chalmers 1996, p.36), concluo que essa tentativa de Searle de apresentar a ausência de consciência como inconcebível não é bem sucedida.

${ }^{38}$ Nesta passagem, estamos concebendo um mundo possível no qual, estritamente falando, não há sódio (isto é, não há esse elemento químico determinado que existe no mundo atual), mas sim uma outra coisa. Trata-se de um mundo logicamente possível, onde valem outras leis naturais, diferentes das de nosso mundo, no qual existe um outro elemento químico, que desempenha um papel causal diferente (em maior ou menor medida) daquele desempenhado pelo sódio em nosso mundo.

39 "A força da implicação, ou necessidade, [...] depende de como o termo modal 'necessariamente' é interpretado, ou, em outras palavras, que mundos possíveis estão envolvidos na quantificação (p. ex. se estamos falando de todos os mundos possíveis, ou apenas dos mundos fisica ou nomologicamente possíveis, etc.)" (Kim 1993, p.144).

${ }^{40} \mathrm{O}$ presente trabalho foi produzido no âmbito do projeto de pesquisa "O naturalismo biológico de John Searle e o fisicalismo não-redutivo", registrado no Departamento de Filosofia da Universidade Federal de Pernambuco (UFPE). Gostaria de agradecer aos pareceristas anônimos da Principia, por suas importantes observações e sugestões.

Principia 16(2): 255-276 (2012). 